\title{
Biomass-Based Composite Foam from Tapioca Starch/Octenyl Succinate Starch Blended with Alpha-Chitin
}

\author{
Manisara Phiriyawirut*, Phatthanachai Hankham, Ratchanok Butsukhon, \\ Udomporn Pongvichai
}

Department of Tool and Materials Engineering, Faculty of Engineering, King Mongkut's University of Technology, Thonburi, Bangkok

Email: *manisara.pee@kmutt.ac.th

How to cite this paper: Phiriyawirut, M., Hankham, P., Butsukhon, R. and Pongvichai, U. (2019) Biomass-Based Composite Foam from Tapioca Starch/Octenyl Succinate Starch Blended with Alpha-Chitin. Open Journal of Composite Materials, 9 , 355-364.

https://doi.org/10.4236/ojcm.2019.94022

Received: August 15, 2019

Accepted: September 21, 2019

Published: September 24, 2019

Copyright (๑) 2019 by author(s) and Scientific Research Publishing Inc. This work is licensed under the Creative Commons Attribution International License (CC BY 4.0).

http://creativecommons.org/licenses/by/4.0/

\begin{abstract}
The research study properties of the starch-based foam from mixed between tapioca starch and octenyl succinate starch (OSA starch), have addition alpha-chitin prepared by hot compression molding method. Tapioca starch with 50\% OSA starch was investigated. For composite foam tapioca starch mixed by adding alpha-chitin at $5 \%-30 \%$ of starch weight, it was found that water absorption was reduced. The higher alpha-chitin content in blending foam, the denser of foam structure observed which resulted in increasing of the foam density. The maximum bending stress of composite starch was decreased, but increasing the maximum bending strain.
\end{abstract}

\section{Keywords}

Starch Foam, Tapioca Starch, Octenyl Succinate Starch, Alpha-Chitin, Composite Foam

\section{Introduction}

Tapioca starch foam is one of natural materials for packaging industry which is produced by kneading the starch with appropriate amount of water to gelatinization, in which the tiny air bubble formation embedded inside of materials [1]. Incomparable properties of starch and polystyrene foam in mechanical and water resistance limits are applied for food packaging, that water resistance is undeniable requirement [2]. An alternative way is using modified starch in order to improve hydrophobicity of the starch as octenyl succinate starch (OSA). The OSA is produced by the reaction of octenyl succinic anhydride, to form a subs- 
tituted group of long hydrophobic hydrocarbon in starch. The main structure of the OSA, natural starch but less susceptible to water, is well compatible with tapioca giving well-homogenized material, and maintaining overall physical properties from the starch foam [3]. One method to overcome water resistance problem of the foam is blending with other types of biodegradable polymers which had been deeply studied such as polycaprolactone (PCL), polylactic acid (PLA) and polybutylene succinate (PBS) [4] [5] [6]. It was found that water resistance of starch composite foams was increasing as incorporated of biodegradable synthetic polymers.

Chitin is a natural polysaccharide which exists in considerable amounts as the exoskeleton of arthropods and fungi. There is using chitin to blend with other materials to improve the brittleness and the elasticity of foam. The outstanding properties of chitin are high toughness, strength, and dimension stability [7]. Thus, it's an excellent choice to blend with tapioca in order to improve the mechanical properties of the foam [8].

In this study, morphology, chemical structure, density, flexural and thermal properties of tapioca starch/octenyl succinate starch blended starch/chitin composite foams were investigated. Water resistance and enzymatic degradation were also studied.

\section{Experimental Methods}

\subsection{Preparation of Blended Starch/Chitin Composite Foams}

Tapioca starch, OSA starch (from Siam Modified Starch Co. Ltd., Thailand), guar gum ( $1 \%$ by weight of blended starch), and magnesium stearate ( $2 \%$ by blended of crosslinked starch) were first dry mixed using a kitchen-aid mixer. Blending ratio of tapioca starch and OSA starch was 50/50 wt\% based on benchmark between mechanical properties and cost [7]. Distilled water was added to the mixture and further mixed for $20 \mathrm{~min}$ at room temperature. Alpha-chitin (18.27\% DD) with size of $0.45-2.00 \mathrm{~mm}$, purchased from Seafresh Industry (Thailand), was also added to the batter. Chitin content was varying between $0 \%$ to $30 \%$. Blended starch/chitincomposite foams were then prepared by hot press molding with $160^{\circ} \mathrm{C}$ on upper plate and $165^{\circ} \mathrm{C}$ on lower plate at 80 $100 \mathrm{~kg}_{\mathrm{f}} / \mathrm{cm}^{2}$ for 2 minutes 15 seconds.

\subsection{Testing}

Before test, the foam specimen, the composite foam specimens were conditioned in a desiccator (10\% - 20\% HR) for 1 week. Chemical structure blended starch/ alpha-chitin composite foams was examined by Fourier transform infrared spectrometer; FT-IR. Density of blended starch/chitin composite foams was examined at room temperature by using Density Determination Kit by using chloroform as liquid media. Morphology of fractured surface of blended starch/chitin composite foams was examined using SEM. Universal Testing Machine with three-point bending method was used in flexural testing (ASTM D 5943-96). The maximum 
load of $2500 \mathrm{~N}$ with a crosshead speed of $2 \mathrm{~mm} / \mathrm{min}$ was applied.

Thermal degradation of blended starch/alpha-chitin composite foams was performed using a Perkin Elmer TGA7, from ambient temperature to $750^{\circ} \mathrm{C}$, at a heating rate of $20^{\circ} \mathrm{C} / \mathrm{min}$ in nitrogen atmosphere.

The water resistance, in term of water absorption and weight loss after water immersion was studied. The procedures were following previous work [5]. Enzymatic biodegradability test of blended starch/alpha-chitin composite foams were investigated in $0.1 \mathrm{M}$ acetate buffer $\mathrm{pH} 6$ containing $\alpha$-amylase $(250 \mathrm{U} / \mathrm{g})$ at room temperature. The tested samples were removed at different time intervals (1 to $24 \mathrm{hr}$.), washed with distilled water before drying at $60^{\circ} \mathrm{C}$ for $5 \mathrm{hr}$. The $\%$ degradability was according to the Equation (1), where $W_{1}$ is the weight of each sample before submersion in amylase media, $W_{2}$ is the weight of the sample after submersion in the $\alpha$-amylase media in its dry state.

$$
\text { Degradation }(\%))=\frac{W_{1}-W_{2}}{W_{1}} \times 100
$$

For density determination, mechanical properties and water resistance test, five replicate specimens were tested for each set.

\section{Results and Discussion}

FTIR is an effective way to characterize functional groups present in polymers. Figure 1 shows the FTIR spectra of chitin and blended starch/alpha-chitin composite foams. It could be found that FTIR spectra of chitin show peaks appearing around $3400 \mathrm{~cm}^{-1}(\mathrm{~N}-\mathrm{H}$ stretching $)$ and $1650(\mathrm{C}=\mathrm{O}$ stretching of amide bond), respectively. Likely, blended starch foams show peaks appearing around $3310 \mathrm{~cm}^{-1}$ (O-H stretching), $2919 \mathrm{~cm}^{-1}$ (C-H stretching), $1735 \mathrm{~cm}^{-1}$ (C=O stretching) and $995 \mathrm{~cm}^{-1}$ (C-O stretching of glycosidic bond), respectively. In addition, adding chitin into the blended starch/chitin composite foams showed the similar IR peak positions (with chitin and starch) and no distinct new peak position could be observed. However, the peak in range of $3300-3400 \mathrm{~cm}^{-1}$ became broadening due to increasing of amide group of chitin.

SEM micrographs of fracture surface of blended starch/alpha-chitin composite foams were showed in Figure 2 and Figure 3 with different magnification. Small and dense of closed cell structure was found at the area closed to surface of blended starch foam, while larger open cell structure was found at the middle layer. The higher chitin content in blending foam, the denser of foam structure observed. Density of foam is increased with existing of chitin in the blend as results of higher viscosity of the starch/chitin blend, and affect to higher surface tension resisting to the expansion of steam in the inner layer of foam. At high magnification, blended starch foams show smooth facture surface reply to brittle of material, while starch/chitin composite foams give roughness facture surface reply to more flexible of composite. In addition, chitin fibers were found well dispersed in starch matrix but no adhesion between alpha-chitin and starch matrix. These results were in good agreement to mechanical properties. 


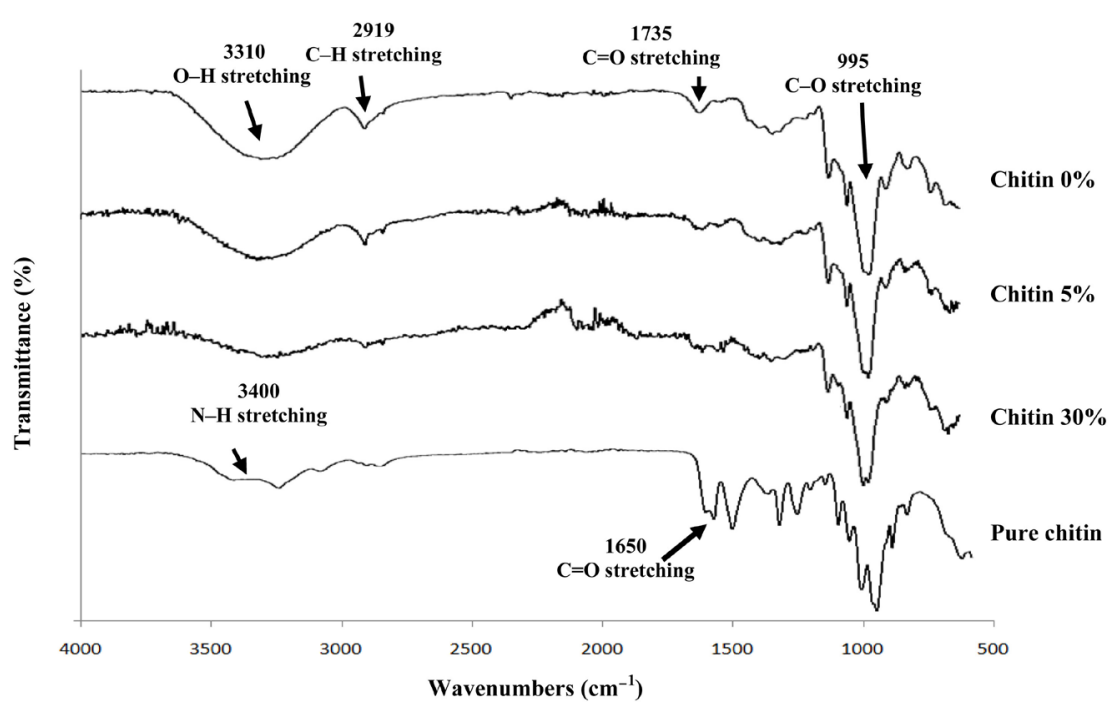

Figure 1. FTIR spectrum of blended starch/alpha-chitin composite foams with different chitin content.

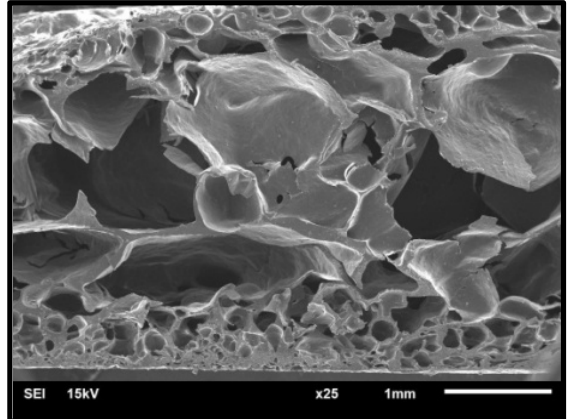

(a)

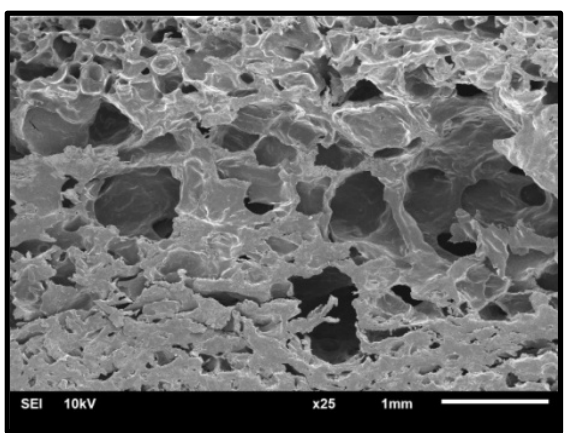

(c)

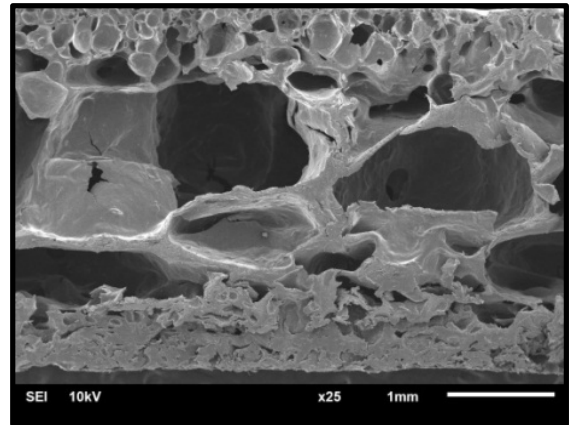

(b)

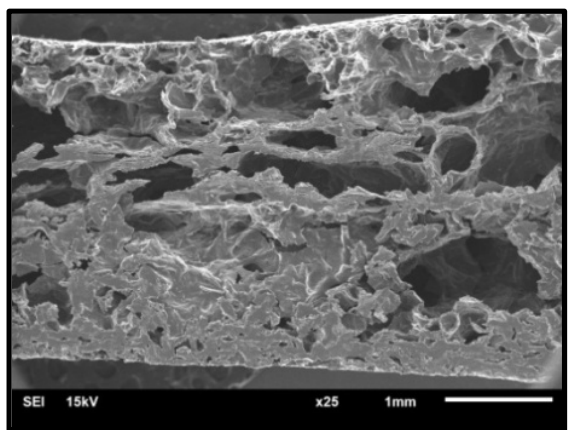

(d)

Figure 2. SEM micrographs of fracture surface of blended starch/alpha-chitin composite foams with different alpha-chitin content (a) $0 \%$; (b) $5 \%$; (c) $20 \%$ and (d) $30 \%$. Magnification $25 \times$.

Table 1 shows the effects of chitin content on density and flexural properties of blended starch composite foams.

Density is an important physical property of foams, which low density is ideal for these products. It was found that the density of blended starch composite foam was increased with increasing chitin content. The adding alpha-chitin to 


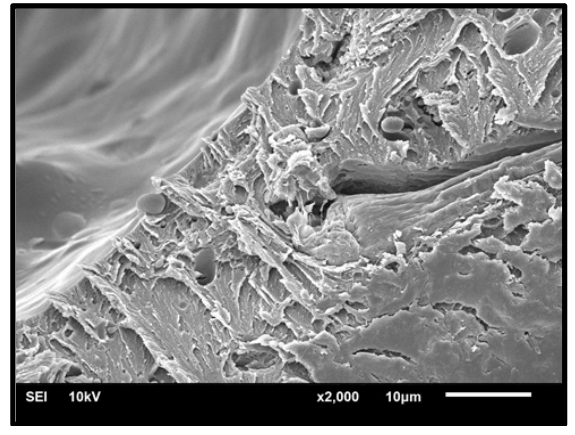

(a)

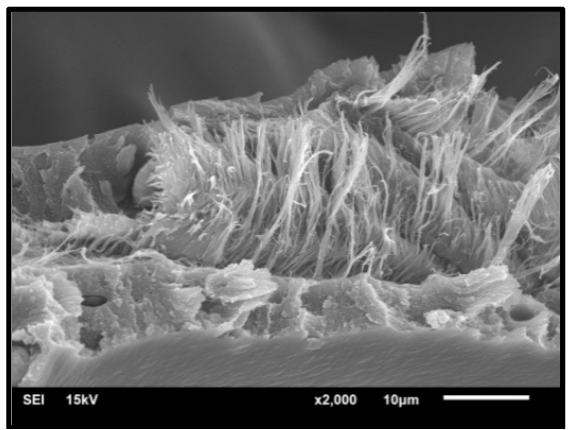

(c)

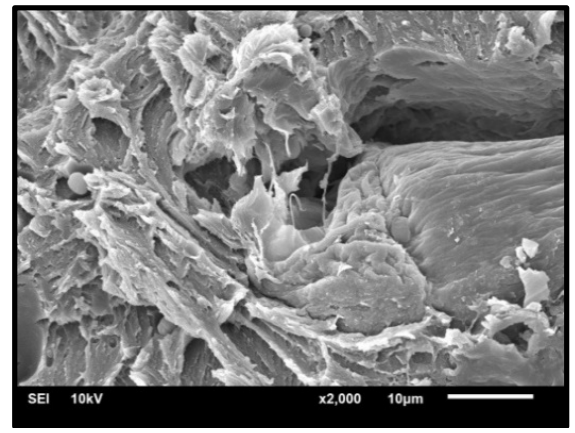

(b)

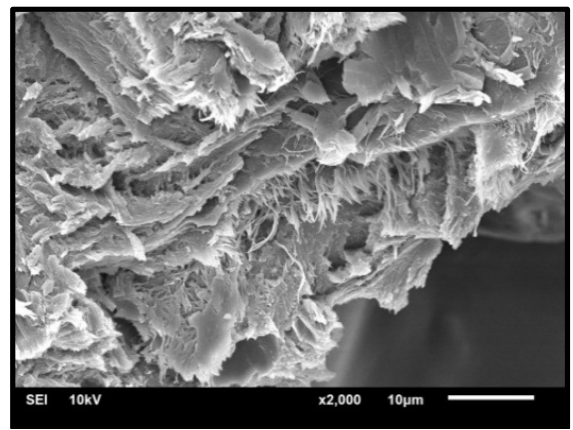

(d)

Figure 3. SEM micrographs of fracture surface of blended starch/alpha-chitin composite foams with different alpha-chitin content (a) $0 \%$; (b) $5 \%$; (c) $20 \%$ and (d) $30 \%$. Magnification $2000 \times$.

Table 1. Density and flexural properties of blended starch/alpha-chitin composite foams with different chitin content.

\begin{tabular}{cccc}
\hline \multirow{2}{*}{$\begin{array}{c}\text { Chitin content } \\
(\%)\end{array}$} & $\begin{array}{c}\text { Density } \\
\left(\mathrm{g} / \mathrm{cm}^{3}\right)\end{array}$ & Strength $(\mathrm{MPa})$ & Strain $(\%)$ \\
\cline { 3 - 4 } & $0.31 \pm 0.01$ & $7.1 \pm 0.4$ & $2.6 \pm 0.5$ \\
5 & $0.39 \pm 0.01$ & $3.4 \pm 0.4$ & $12.0 \pm 0.4$ \\
10 & $0.43 \pm 0.01$ & $4.9 \pm 0.4$ & $11.8 \pm 0.6$ \\
20 & $0.44 \pm 0.02$ & $5.7 \pm 0.5$ & $11.7 \pm 0.4$ \\
30 & $0.57 \pm 0.02$ & $4.6 \pm 0.4$ & $11.6 \pm 0.6$ \\
\hline
\end{tabular}

the batter induced the increase in the viscosity causes the batter to be less expandable, giving rise to smaller average cell size, thicker cell wall, and higher density. According to Table 1, the density for starch composite foams increased with increasing alpha-chitin content. The result was agreed to the previous work [8] [9].

It is obvious that the chitin blended starch foam can reduce flexural strength but as increasing chitin content up to $20 \%$, flexural strength increased and decreased again at $30 \%$. However, flexural strain increases by addition of chitin but independent to chitin content. The improvement of flexibility of composite foam was also good agreed with SEM results which seem that chitin added composite foam show less brittle fracture than that of starch foam. 
It is obvious that the chitin blended into blended starch foam can improve flexibility, however, less surface wettability of the chitin-starch phase was found, and cause little improvement in this property. These results were different from previously work [8] which adding chitin can improve flexural strength but decrease flexural strain of tapioca starch composite foam.

Thermal stability and degradation temperature of blended starch/alpha-chitin composite foams were examined using TGA technique as shown in Figure 4 and Table 2.

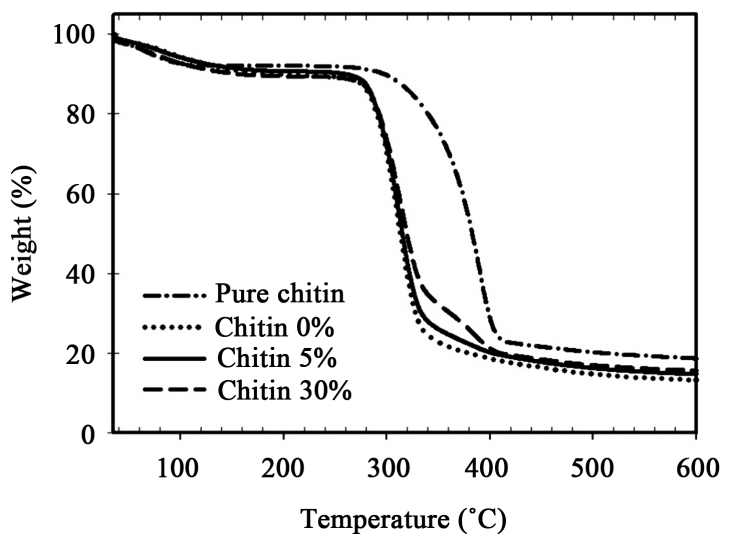

(a)

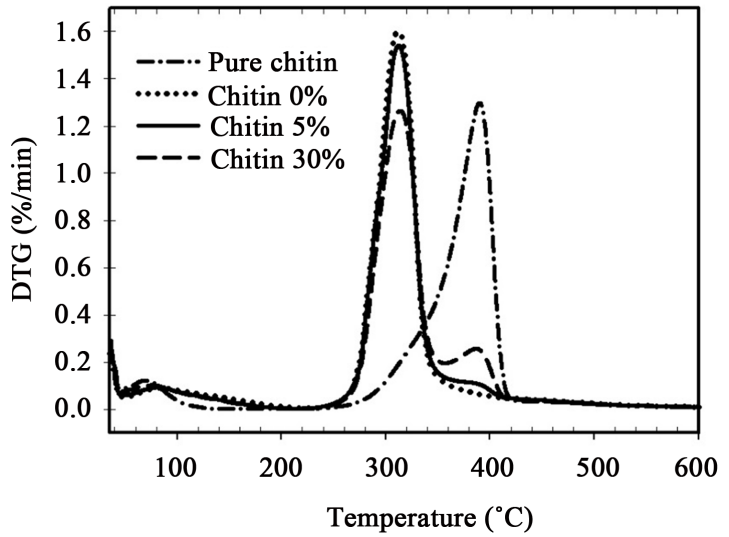

(b)

Figure 4. TGA thermograph of blended starch/alpha-chitin composite foams with different alpha-chitin content (a) TGA thermograph and (b) DTG thermograph.

Table 2. Thermal degradation of blended starch/alpha-chitin composite foams with different chitin content.

\begin{tabular}{ccccccc}
\hline \multirow{2}{*}{ Sample } & \multicolumn{2}{c}{$1^{\text {st }}$ degradation } & $2^{\text {nd }}$ degradation & \multicolumn{2}{c}{$3^{\text {rd }}$ degradation } \\
\cline { 2 - 7 } & $\mathrm{T}\left({ }^{\circ} \mathrm{C}\right)$ & $\mathrm{W}(\%)$ & $\mathrm{T}\left({ }^{\circ} \mathrm{C}\right)$ & $\mathrm{W}(\%)$ & $\mathrm{T}\left({ }^{\circ} \mathrm{C}\right)$ & $\mathrm{W}(\%)$ \\
\hline Blended starch foam & 70 & 8.7 & 291 & 77.9 & - & - \\
Blended starch foam + 5\% alpha-chitin & 68 & 7.8 & 290 & 70.9 & 343 & 6.2 \\
Blended starch foam + 30\% alpha-chitin & 65 & 8.1 & 289 & 56.8 & 342 & 17.9 \\
Alpha-chitin & 62 & 5.7 & - & - & 298 & 74.6 \\
\hline
\end{tabular}


The first weight loss, at around $65^{\circ} \mathrm{C}-70^{\circ} \mathrm{C}$ was related to the volatilization of water which was observed for both chitin and starch blended composite foam. The maximum degradation step approximately $290^{\circ} \mathrm{C}$ was assigned to the degradation of starch [10]. Chitin also showed the last onset degradation step at the temperature around $298^{\circ} \mathrm{C}$.

The addition of chitin into composite slightly affect to the 1st degradation temperature of water volatilization temperature due to the interrupt to water absorption of starch, then ease of volatilization in the $1^{\text {st }}$ degradation, and slightly weight loss to pure blend starch foam. There is no significant changed in the $2^{\text {nd }}$ degradation temperature from the composite blend with chitin. This result is in a good agreement to the SEM image of the separation phase between these two materials, thus the existing of chitin would not affect to the degradation of starch. The $3^{\text {rd }}$ degradation temperature of chitin in composite foam has no significant difference when the amount of chitin in the composite is changed, but the degradation temperature of chitin in the composite foam is higher than degradation temperature of pure chitin. There is similarity of structure between chitin and starch, and there is bonding with $1-4$ glycocidic bonding, and this may the reason of higher degradation temperature to pure chitin when the starch exists in the chitin structure.

High water absorption of starch-based material is drawback, and improvement such property is the most important to develop application for this material. The effect of alpha-chitin content on water resistance of blended starch/chitin composite foams was studied by determined the percentages of water absorption and percentage of weight loss as shown in Figure 5.

It is significantly lower water absorption in blended starch/chitin composite foams comparing to unfilled chitin composite foams. Increasing of alpha-chitin content improves water resistance of the blend foams. Improvement of water resistance of alpha-chitin-filled composite foams was corresponding to the denser foam morphology which retarded water absorption. The other reason was the high crystalline structure of alpha-chitin which results in hydrophobic character of chitin in comparison to starch hydrophilic properties [11]. This led to high hydrophobicity of the alpha-chitin-filled composite foams when comparing the unfilled composite foam. This result was in agreement to previous study [6]. The effect of chitin content in improving water resistance was supported by results of percentage of weight loss as shown in Figure 5.

Enzymatic degradation of blended starch/alpha-chitin composite foams with different chitin content was tested by $\alpha$-amylase in vitro at $60^{\circ} \mathrm{C}$ and the results are expressed as a function of reaction time in Figure 6. All the foam specimens investigated exhibited a monotonic increase in the percentage of weight loss with increasing reaction time. An adding alpha-chitin content between 5\% - 30\%, the percentage of weight loss from enzymatic degradation was found to decrease but effect of content was not significant.

$\alpha$-Amylase is endoamylases which catalyze the hydrolysis of internal $\alpha$-1,4-glycosidic linkages in the starch in a random manner. The hydrolysis of 


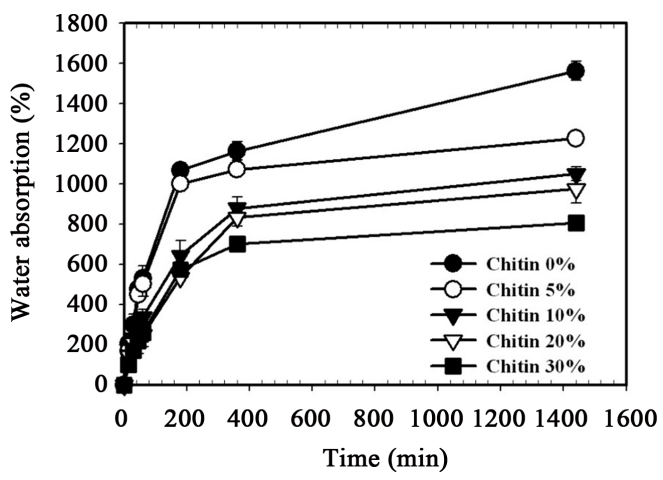

(a)

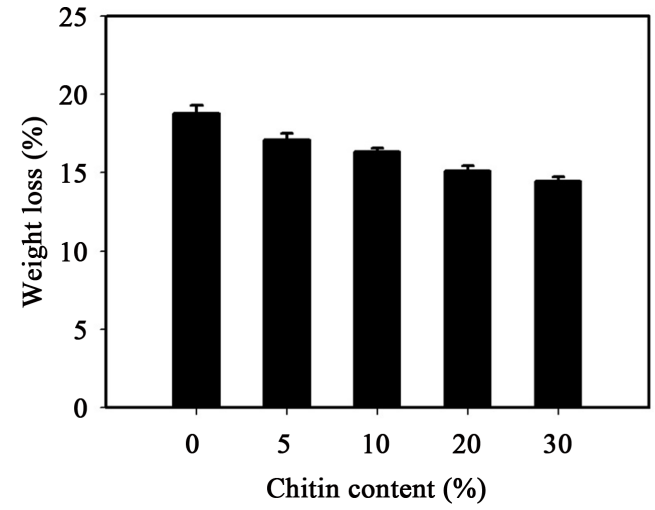

(b)

Figure 5. Water resistance of blended starch/alpha-chitin composite foams with different alpha-chitin content (a) Water absorption and (b) Percentage of weight loss after immersed in water at $25^{\circ} \mathrm{C}$ for $24 \mathrm{hrs}$.

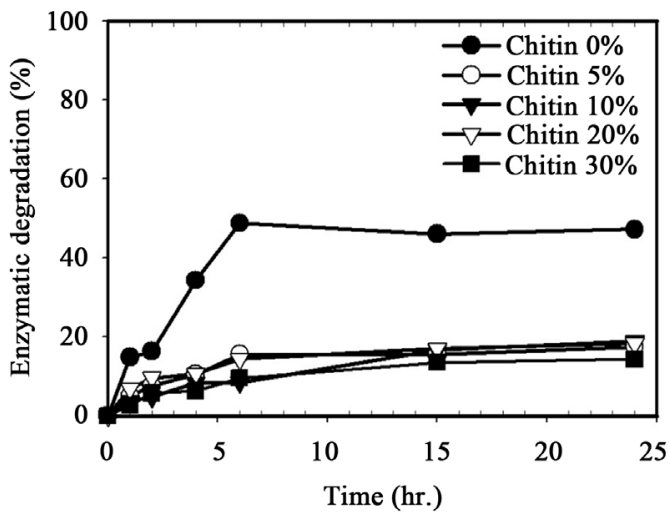

Figure 6. Enzymatic degradation of blended starch/chitin composite foams with different chitin content.

tapioca/OSA blended starch by $\alpha$-amylase will further weaken as the present of alpha-chitin phase. In addition, as $\alpha$-amylase solution contains distilled water, it is believed that during enzymatic tests, starch composite foams with alpha-chitin could absorb less water/ $\alpha$-amylase solution than foam without alpha-chitin composite does. This may retard the penetration of $\alpha$-amylase into the foams and subsequently reduce the $\alpha$-amylase attack on the starch. 


\section{Conclusions}

In this research, biomass-based blended starch/chitin composite foams were prepared by hot press molding. The effect of alpha-chitin content $(5 \%-30 \% \mathrm{wt})$ on the density, flexural properties, thermal stability and water resistance of tapioca starch/OSA starch blended starch/chitin composite foams were investigated. It was found that addition of alpha-chitin increases density, improves water resistance and little improves flexural strain of the blended starch composite foams. However, no effect of chitin on chemical structure and thermal degradation of blended starch/chitin composite foams was observed.

The optimum content of chitin for this biomass-based blended starch/chitin composite foam is at $20 \%$. At this chitin content gave reduce in flexural strength while the improvement of flexural strain and water resistance. However, higher chitin content was not good for making foam because higher viscosity of the battle causes process difficulty, and it gives higher density of foam.

\section{Conflicts of Interest}

The authors declare no conflicts of interest regarding the publication of this paper.

\section{References}

[1] Tiefenbacher, K.F. (1993) Starch-Based Foamed Materials: Use and Degradation Properties. Journal of Macromolecular Science, Part A, 30, 727-731. https://doi.org/10.1080/10601329308021258

[2] Glenn, G.M., Orts, W.J., Nobes, G.A.R. and Gray, G.M. (2001) In Situ Laminating Process for Baked Starch-Based Foams. Industrial Crops and Products, 14, 125-134.

[3] Simsek, S., Martinez, M.O., Marefati, A., Sjöö, M. and Rayner, M. (2015) Chemical Composition, Digestibility and Emulsification Properties of Octenyl Succinic Esters of Various Starches. Food Research International, 75, 41-49.

[4] Preechawong, D., Peesan, M., Rujiravanit, R. and Supaphol, P. (2004) Characterization of Starch/Poly( $\varepsilon$-Caprolactone) Hybrid Foams. Polymer Testing, 23, 651-657. https://doi.org/10.1016/j.polymertesting.2004.01.011

[5] Preechawong, D., Peesan, M., Rujiravanit, R. and Supaphol, P. (2005) Characterization of Starch/Poly(L-Lactic Acid) Hybrid Foams. Carbohydrate Polymers, 59, 329-337.

[6] Phiriyawirut, M., Mekaroonluck, J., Hauyam, T. and Kittilaksanon, A. (2016) Biomass-Based Foam from Crosslinked Tapioca Starch/Polybutylene Succinate Blend. Journal of Renewable Materials, 4, 185-189. https://doi.org/10.7569/JRM.2015.634121

[7] Phiriyawirut, M., Duangsuwan, T., Uenghuab, N. and Meena, C. (2017) Effect of OctenylSuccinate Starch on Properties of Tapioca Thermoplastic Starch Blends. Key Engineering Materials, 751, 290-295. https://doi.org/10.4028/www.scientific.net/KEM.751.290

[8] Phiriyawirut, M. and Tooljinda, P. (2009) Alpha-Chitin Reinforced Tapioca Starch-Based Composite Foam. Proceeding of Asian Workshop on Polymer Processing (AWPP2009), Malaysia, 1-4 December 2009. 
[9] Shogren, R.L., Lawton, J.W. and Tiefenbacher, K.F. (2002) Baked Starch Foams: Starch Modifications and Additives Improve Process Parameters, Structure and Properties. Industrial Crops and Products, 16, 69-79. https://doi.org/10.1016/S0926-6690(02)00010-9

[10] Curvelo, A.A.S., de Carvalho, A.J.F. and Agnelli, J.A.M. (2001) Thermoplastic Starch-Cellulosic Fibers Composites: Preliminary Results. Carbohydrate Polymers, 45, 183-188. https://doi.org/10.1016/S0144-8617(00)00314-3

[11] Gaspar, M., Benko, Z., Dogossy, G., Reczey, K. and Czigany, T. (2005) Reducing Water Absorption in Compostable Starch-Based Plastics. Polymer Degradation and Stability, 90, 563-569. https://doi.org/10.1016/j.polymdegradstab.2005.03.012 